\title{
ARTIC LES
}

\section{ASSESS THE KNOWLEDGE OF FIRST DEGREE RELATIVES REGARDING HOME CARE OF PSYCHIATRIC PATIENTS}

\author{
Mr. Vikas Kumawat* | Mrs. Lolita lal**
}

*HOD Regency institute of Nursing Kanpur, Uttar Pradesh, India.

**Principal Saaii institute of Nursing Chobepur Kanpur, Uttar Pradesh, India.

DOI: http://doi.org/10.47211/idcij.2021.v08i01.006

\begin{abstract}
This study was conducted to "Assess the knowledge of first degree relatives regarding home care of psychiatric patients in Gwalior Mansik Arogyashala. This topic focuses primarily the adaptation of the research method for the study. Research methodology gives a bird's eye view of the entire process of tackling a research problem in a scientific and systematic way.

Family members play a major role in providing care giving assistance to elderly persons and their families this include both the provision of direct and indirect care.

Mental illness is an age old problem of mankind. It is documented in all cultures around the world in the oldest literature. Till recently, the actual cause of mental illness was not known and there were few effective treatment methods. Mental patients were often a source of disturbance to others. Mental health, rather than just those suffering from a mental illness, should be a problem for all of us. Care of a psychiatric patient based on nonresidential psychiatric services in mental asylum that provide rehabilitation or care for people affected by a mental illness or psychiatric disabilities.
\end{abstract}

Key Words: Mental illness, effective treatment, design, and sample, home care, psychiatric.

\section{ABOUT AUTHORS:}

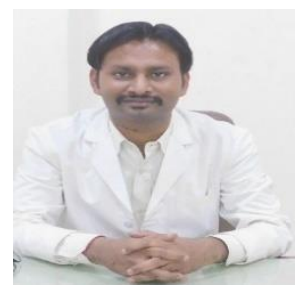

Author Mr. Vikas Kumawat is HOD, Regency Institute of Nursing Kanpur, Uttar Pradesh, India.

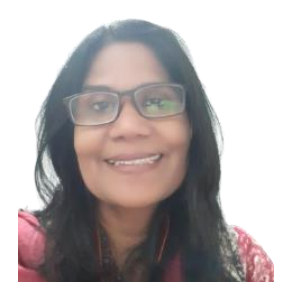

Author Mrs. Lolita Lal is Principal Saaii College of Medical Science and Technology, Kanpur, Uttar Pradesh, India. 


\section{ARTIC LES}

\section{INTRODUCTION}

World health originations had chosen the theme on Mental health "Stop exclusion - dare to care" during the year 2001, to focus worldwide attention on the issues related to mental health. Mental illnesses rank.

Because of the issue of a mentally disabled global crisis. Mental analysis studies indicated high prevalence rate of mental disorders in the community (58.2/1000). Among the leading illness and disability the world over Reddy NG (1992) stated that mental health is about enhancing competence of the individuals and family and enables them to achieve their self - determine goal. Mental health should a concern for all of us, rather than only for those who suffer from a mental disorder. Mental health, rather than just those suffering from a mental illness, should be a problem for all of us. Care of a psychiatric patient based on non-residential psychiatric services in mental asylum that provide rehabilitation or care for people affected by a mental illness or psychiatric disabilities. Family members play a major role in providing care giving assistance to elderly persons and their families this include both the provision of direct and indirect care.

1. Mental illness is an age old problem of mankind. It is documented in all cultures around the world in the oldest literature. Till recently, the actual cause of mental illness was not known and there were few effective treatment methods. Mental patients were often a source of disturbance to others. The initial attempts were to distinguish them from others and hold them close to each other in places called 'asylums'. This did not solve the problem. When these patients had to live away from their family members and stay within the limits of the four walls of the mental hospitals, they often deteriorated. Their suffering increased. This lead to fear of 'mental hospital'. The general public hesitated to bring their mentally ill relatives to these hospitals because they think that they can take care much bitterly or can handle them successfully at home.

2. Mental health is not exclusively a matter of relation between persons, it is also a matter of relation of the individuals towards the family he lives in, towards the society of which the family is a part, and towards the total institutions which for a large part guide his life, determine his way of living, working, leisure, and the way he earns and spends his money, the way he sees happiness, stability in security.

\section{NEED OF THE STUDY:}

Baronet conducted a critical review of the academic literature on variables correlated with the burden of caregivers of mental illness. This study review identifies aspects of care giving that are most burdensome to caregivers. It defines the essence of the relationship between variables and various aspects of the burden of the caregiver and identifies mixed results that are potentially important to the burden of the caregiver.

Family members play a significant role in delivering care that supports elderly people and their families. This requires both direct treatment, such as washing, and indirect care, such as running errands, cooking meals, and doing housework. It was found that sons as caregivers reported significantly less burden than risk daughters or other relatives.

Rose LE (1996) conducted a study on families of psychiatric patients a critical review and future research designs. The study explains that the rapidly changing health care environment suggests that our understanding of families, responses to mental illnesses need to be re-examined for current relevance and new insights. This essay reviews the literature to date objectively and addresses gaps in information related to the experience of mental illness and treatment in the family.

Nordentoft M et. al., (1993) conducted a study on relatives of psychotic patients' effects of group discussion and group education. The 40 samples were questioned about the level of satisfaction of strain perception, attitude and attitudes in relation to mental illness and the family's emotional atmosphere. The siblings complained of inconsistencies in the patient's care. It was concluded that better cooperating between family members and psychiatric department/ community mental health nursing department increase the relatives' ability to handle problems to the patients' disease.

Hence the researcher felt there was a need to conduct a study on knowledge on first degree relatives regarding care of psychiatric patients at homes. 


\section{ARTIC LES}

\section{STATEMENT OF THE PROBLEM}

"A descriptive study to assess the knowledge of first degree relatives regarding home care of psychiatric patients in Gwalior Mansik Arogyashala, Gwalior M.P."

\section{OBJECTIVES OF THE STUDY}

${ }^{*}$ To assess the level of knowledge of first degree relatives regarding home care of psychiatric patients at home.

*To find out association between level of knowledge regarding home care of psychiatric patient and selected demographic variables.

\section{RESEARCH METHODOLOGY}

The methodology of a research study is defined as "the way in which the relevant data is collected in order to answer the research question or analyse the research issue." It enables the research to project a blue print of the research undertaken" "research methodology involves a systematic procedure by which the researcher starts from the initial identification of the problem to its final conclusion." ${ }^{12}$

The methodology of research is a way to address the issue of research systematically. It comprises, statement of the problem objectives of the study the hypothesis that have been formulated, the variables under study methods used for data collection and the statistical methods used for reviewing data and the logic behind it.

This study deals with the brief description of the different steps undertaken by the investigator for the study. It includes the research approach, research design, variables, setting of the study, population, sample and sampling techniques, development of tool, description of tool, content validity, pre-testing of the tool, pilot study and data collection procedure and plan for data analysis.

RESEARCH APPROACH AND DESIGN non experimental

SETTING OF THE STUDY: non probability convenient sampling method.

SAMPLE SIZE: 100 first degree relatives of psychiatric patients

SAMPLING TECHNIQUE Non probability convenient sampling

\section{SAMPLE SELECTION CRIRERIA}

1. First degree relatives of psychiatric patients.

2. Who are willing to participate in the study?

DATA ANALYSIS AND INTERPRETATION

Table .1 Distribution of respondents according to Age in Years

\begin{tabular}{|l|c|c|}
\multicolumn{1}{|c|}{ Variable (Age In Years) } & No of respondents & Percentage \\
\hline $25-30$ yrs. & 36 & 36.00 \\
\hline $31-35$ yrs. & 28 & 28.00 \\
\hline $36-40$ yrs. & 26 & 26.00 \\
\hline$>41 \mathrm{yrs}$ & 10 & 10.00 \\
\hline
\end{tabular}




\section{ARTIC LES}
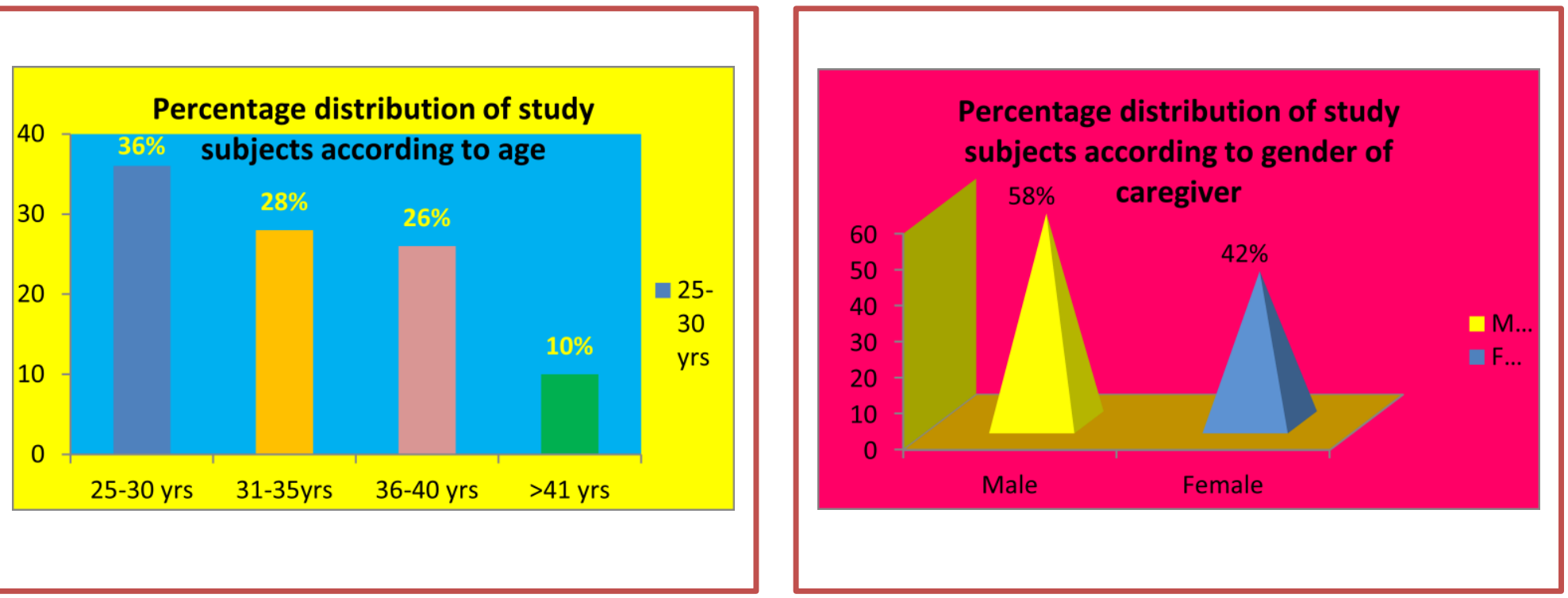

Table.2 Distribution of respondents according to sex of caregiver $\mathrm{N}=100$

\begin{tabular}{|l|c|c|}
\hline \multicolumn{1}{|c|}{$\begin{array}{c}\text { Variable (Sex of the } \\
\text { caregiver) }\end{array}$} & $\begin{array}{c}\text { No of } \\
\text { respondents }\end{array}$ & Percentage \\
\hline Male & 58 & 58.00 \\
\hline Female & 42 & 42.00 \\
\hline
\end{tabular}

Table .3 Distribution of respondents according to marital status

\begin{tabular}{|l|c|c|}
\hline \multicolumn{1}{|c|}{$\begin{array}{c}\text { Variable (Marital } \\
\text { status) }\end{array}$} & $\begin{array}{c}\text { No of } \\
\text { respondents }\end{array}$ & Percentage \\
\hline Married & 40 & 40.00 \\
\hline Unmarried & 52 & 52.00 \\
\hline Divorces & 8 & 8.00 \\
\hline
\end{tabular}




\section{ARTIC LES}

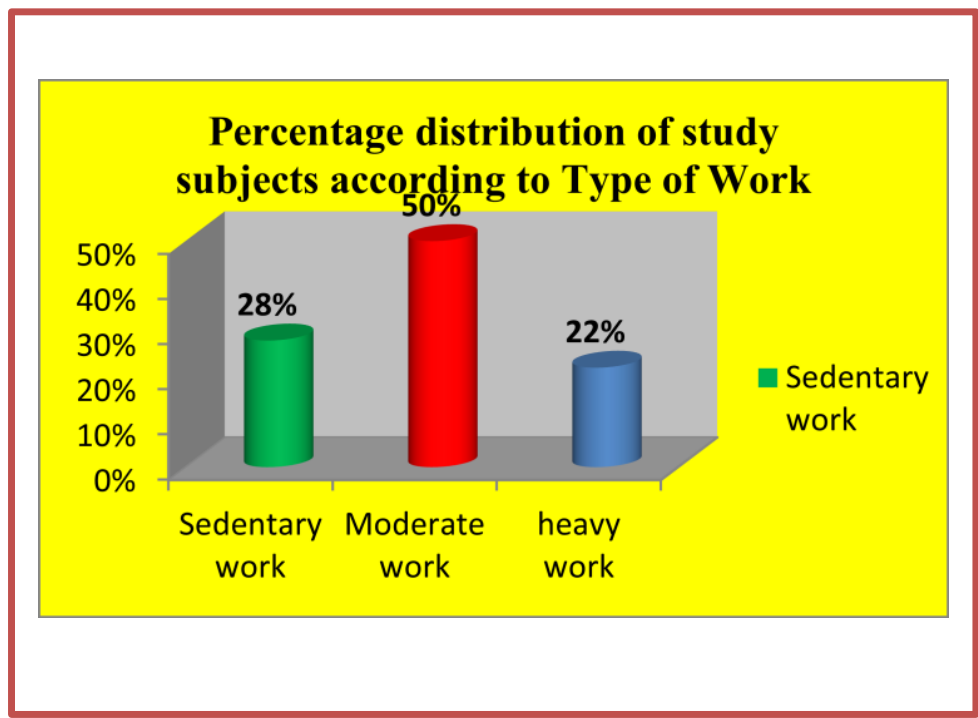

Distribution of respondents according to Type of Work

\begin{tabular}{|c|c|c|}
\hline $\begin{array}{c}\text { Variable } \\
\text { (Type of Work) }\end{array}$ & No of respondents & Percentage \\
\hline Sedentary work & 28 & 28.00 \\
\hline Moderate work & 50 & 50.00 \\
\hline Heavy work & 22 & 22.00 \\
\hline
\end{tabular}

\section{Percentage distribution of study subjects according to Marital status}

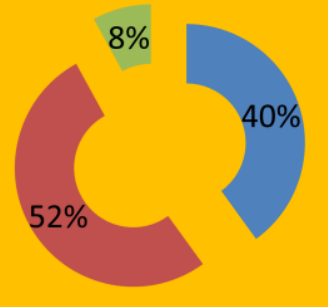

Married

- Unmarried

Divorces
Distribution of respondents according to marital status

\begin{tabular}{|c|c|c|}
\hline $\begin{array}{c}\text { Variable } \\
\text { (Marital status) }\end{array}$ & $\begin{array}{c}\text { No of } \\
\text { respondents }\end{array}$ & Percentage \\
\hline Married & 40 & 40.00 \\
\hline Unmarried & 52 & 52.00 \\
\hline Divorces & 8 & 8.00 \\
\hline
\end{tabular}




\section{ARTIC LES}

\section{SUGGESTIONS:}

1. Some educating street play, drama, and other public educating programmes in the community and college should arrange to bring awareness among the students and community people regarding home care of psychiatric patients.

2. Regular in-service/ refresher course on universal precautions should be implemented in colleges and community.

3. In schools, colleges and community health education can be given regarding mental illness.

4. Nurses should upgrade their knowledge regarding mental illness in order to give excellent education.

5. Mass media, and other medias should strictly avoid giving advertise in favour of stimulating relatives or community peoples regarding home care of mentally ill patient.

\section{RECOMMENDATIONS:}

1. A study on the knowledge of nursing personnel regarding mental illness may help to the relatives.

2. A study on the attitude and willingness of nursing personnel regarding mental illness may be helpful for the family members.

\section{CONCLUSIONS}

Majority of samples were from age group of 25-30 years having high knowledge i.e. 19\%, middle class education having high knowledge i.e. $21 \%$, male i.e. $38 \%$ has high knowledge, $30 \%$ with high knowledge were married, $40 \%$ earning 3001-6000per month, 30\% got information from film and similar no. from television, $40 \%$ were parents who were having high knowledge about home care of mentally ill patient

\section{REFERENCES}

1. Flaskerud JH, Kviz FJ. Rural attitudes towards knowledge of mental illness and treatment resources. Hosp community psychiatry 1983 mar; 34(3): 229-33.

2. Park K. Text book of Preventive and Social medicine. $18^{\text {th }}$ ed. Jabalpur. M / s Banarsidas Bhanot; 2005.p-632. 